\title{
Investigation of Ultra-high Performance Concrete Under Static and Blast Loads
}

\author{
Jun $\mathrm{Li}^{*}$, Chengqing Wua,b, Hong $\mathrm{Hao}^{c}$ and $\mathrm{Yu} \mathrm{Su}^{\mathrm{a}}$ \\ aschool of Civil, Environmental and Mining Engineering, \\ the University of Adelaide, SA, Australia 5005 \\ bTCU-UA (Tianjin Chengjian University-University of Adelaide) \\ Joint Research Centre on Disaster Prevention and Mitigation \\ cDepartment of Civil Engineering, Curtin University, \\ WA 6845, Australia
}

Received on 19 January 2015; Accepted 23 March 2015

\begin{abstract}
Conventional concrete works as an important construction material. However, conventional concrete is known to be brittle and prone to tensile failure and cracks. To overcome such defects and improve the dynamic performance of concrete against extreme loading conditions, concrete with different additions and formulae have been developed. In a recent study, to develop ultra-high performance concrete (UHPC) material with better strength and crack control ability, super fine aggregates with high pozzolanic effect were mixed into the steel fibre reinforced concrete instead of the traditional graded coarse aggregates. Furthermore, to achieve high early age strength, nanoscale additives which can accelerate the hydration process of the ordinary Portland cement were also introduced into the concrete composite. A series of uniaxial compression and four-point bending tests had been performed in the laboratory to get the material properties of this innovative concrete material. Great improvement of the concrete uniaxial compressive strength and flexural tensile strength was observed. Field blast tests were carried out on columns made of this UHPC material. Superior blast resistance performance was observed. In the current study, based on the available test data, numerical models are developed and numerical simulations are carried out. The simulation results are found to comply well with the experimental results.
\end{abstract}

Key words: steel fibre, nano-additive, UHPC, static tests, blast tests, numerical simulation

\section{INTRODUCTION}

Although working as a widely used construction material, conventional concrete is known to be inclined to brittle damage with extensive cracks under static or dynamic loads. Researchers have been working dedicatedly on the development of new concrete composites in the past decades. 
Compared to normal strength concrete, ultra-high performance concrete (UHPC) or reactive powder concrete is known for its high strength, high ductility and high durability. It allows construction of sustainable and economic buildings with a slim and aesthetic design. UHPC material achieves a high tensile strength as well as a ductile tensile behaviour through an optimized combination of high-strength concrete and high-strength fibres. After initial crack formation, the stress is allowed to transfer from matrix to fibres which significantly reduce the crack propagation. In recent decades, with the rising of terrorism activity, buildings as well as the personnel they shield are under potential threat from the explosions or high velocity impacts. Researchers have made significant effort on developing new and affordable UHPC material resisting such blast and impact loads. Recently, Wu et al. conducted blast tests on UHPC slabs [1] and compared them with control samples made with normal strength concrete, and they concluded that combination of high strength concrete with steel fibre can significantly increase the blast loading resistance of structural components. Bindiganavile et al. [2] observed the impact response of UHPC material through drop weight tests, and direct comparisons were made with conventional normal strength fibre reinforced concrete. Test results indicated that UHPC was approximately two times stronger than normal strength fibre reinforced concrete.

Until now, optimization of the material composition of UHPC is still widely studied in order to cater for the need of even better performance such as early age workability, impact and explosive loading resistance, fire and corrosion resistance and aggressive chemical resistance.

Fibre material is one of the most important composites in UHPC matrix. Since the beginning of the 20th century, asbestos fibre was used in concrete cement to enhance the mechanical, chemical and thermal resistance. However, asbestos was later known to be toxic and its usage was widely banned. Considerable research had been committed to finding an alternative fibre to replace asbestos in fibre cement products [3]. Ever since 1960s, fibre materials like steel fibre, glass fibre and synthetic fibre took the stage and had been mixed into the concrete matrix to reduce the permeability and enhance its crack control ability. Riguad et al. [4] studied post-cracking behaviour of high performance concrete containing glass fibres, and they found the durability and ductility of this material maintained after accelerated aging tests in $50{ }^{\circ} \mathrm{C}$ water. Chen and Chanvillard [5] used 2.2 vol. \% glass fibres in concrete composites to achieve an improved tensile strength and material ductility. Microstructure characterization by scanning-electron microscopy (SEM) and mercuryintrusion porosimetry (MIP) furthermore points to the high durability of the glass fibre reinforced concrete. Zheng et al. [6] discussed characteristics of various synthetic fibres and the behaviour of concrete reinforced with each of these fibres, and they reviewed research on the performance of synthetic fibre-reinforced concrete based on polyethylene (PE), polypropylene (PP), acrylics (PAN), poly (vinyl alcohol) (PVA), polyamides (PA), aramid, polyester (PES) and carbon reinforcements. Buratti et al. [7] described the results of an experimental investigation on the performances of concrete specimens reinforced with either steel or macro-synthetic fibres under three-point bending. In general steel fibres were more efficient in increasing the toughness of concrete than macro-synthetic fibres. Ye et al. [8] experimentally investigated the mechanical behaviour of concrete reinforced by hybrid different shapes of steel fibres. The largest fracture energy and bending toughness were obtained with hybrid-fibres, where the volume ratio of long ultra-fine fibre was $1.5 \%$, and the ratio of long end-hooked fibre was $0.5 \%$. The hybrid-fibres had generated positive intermixing effect. Bindiganavile and Banthia [9] pointed out that under both static and lowrate impact loads, the predominant failure mode of steel fibre reinforced concrete material 
was the steel fibre pull-out. To increase the bonding between the concrete and steel fibre material, $\mathrm{Xu}$ et al. [10] proposed spiral shaped steel fibres, and the impact tests had demonstrated that concrete specimens reinforced with spiral shaped fibres displayed the best ultimate compressive strength, post-failure strength and energy-absorption capacity among all steel fibre reinforced test specimens.

Advances in material science and nanotechnology have led to a renewed interest in reformulating the existing materials. It was noticed that several phenomena including statistical mechanical effects and quantum mechanical effects become pronounced as the size of the system decreases. Addition of nanoscale size particles results in significantly improved material properties without much change of the material composition.

As depicted in Figure 1, nano sized particles have a high surface area to volume ratio which enables a potential of tremendous pozzolanic effect. For cement based material like concrete, calcium silicate hydrate $(\mathrm{C}-\mathrm{S}-\mathrm{H})$ is the main product during the hydration process and is primarily responsible for the material strength. Nano particles are typically high effective pozzolanic material and addition of such material into the cement paste improves the microstructure of the paste and reduces calcium leaching as these materials react with Calcium Hydroxide Crystal and form additional C-S-H gel.

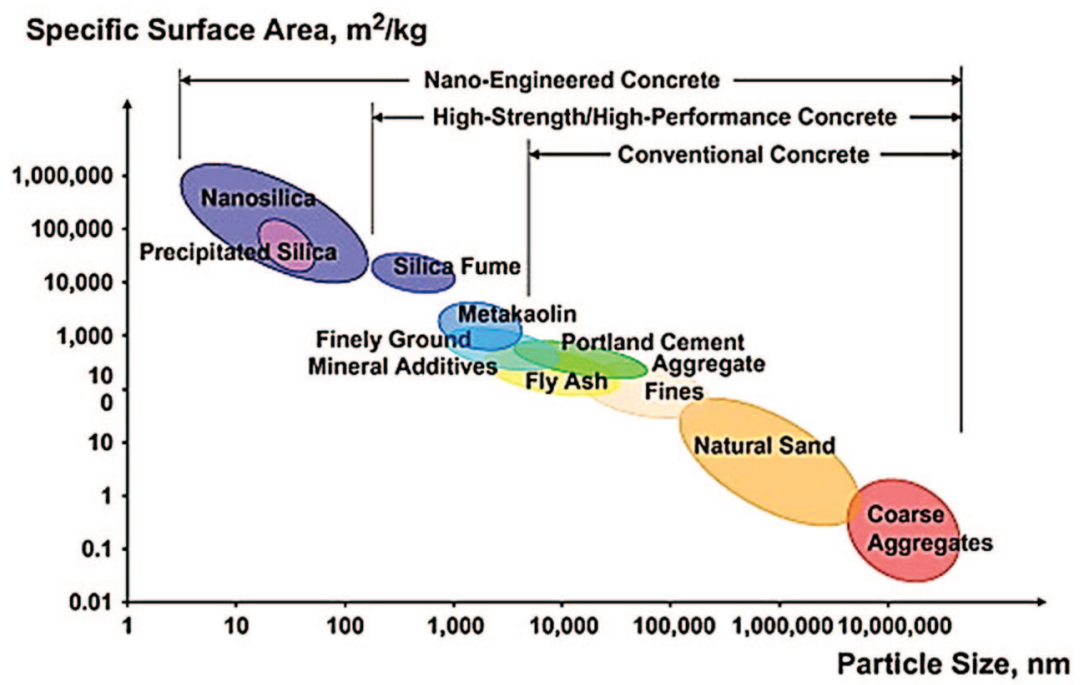

Figure 1. Particle size and specific surface area related to concrete materials. Adapted from (11)

Qing et al. [12] discussed the influence of nano- $\mathrm{SiO}_{2}$ addition on properties of hardened cement paste as compared with silica fume. Results indicated that the pozzolanic activity of nano- $\mathrm{SiO}_{2}$ is more obvious than that of silica fume, and the cement hydration process was accelerated with nano particles addition. Compressive strengths and bond strengths of pasteaggregate interface incorporating nano material were obviously higher than those incorporating silica fumes, especially at early ages. Through water permeability test, Ji [13] pointed out that the microstructure of concrete with nano- $\mathrm{SiO}_{2}$ is more uniform and compact than that of normal concrete, and the incorporation of nano- $\mathrm{SiO}_{2}$ can improve the resistance of water penetration of concrete. Li et al. [14] investigated the properties of cement mortars blended with nanoparticles nano- $\mathrm{SiO}_{2}$ or nano- $\mathrm{Fe}_{2} \mathrm{O}_{3}$. The experimental results showed that the compressive and flexural strengths measured at the 7 th day and 28th day of the cement 
mortars mixed with the nano-particles were higher than that of a plain cement mortar. They concluded that it was feasible to add nano-particles to improve the mechanical properties of concrete. Through tests on cylindrical specimens with different column fraction of nano$\mathrm{Al}_{2} \mathrm{O}_{3}$, Li et al. [15] found that elastic modulus and compressive strength of mortar with nano- $\mathrm{Al}_{2} \mathrm{O}_{3}$ were increased. Liu et al. [16] added nano- $\mathrm{CaCO}_{3}$ into the cement paste and the experimental results showed that nano- $\mathrm{CaCO}_{3}$ had no effect on water requirement of normal consistency of cement. However, with the increase of nano- $\mathrm{CaCO}_{3}$ content, the flowability decreased and the setting time of fresh cement paste was shortened. Flexural strength as well as compressive strength increased with the addition of nano- $\mathrm{CaCO}_{3}$ at the age of 7 days and 28 days. Sanchez and Sobolev [17] made a review on nanotechnology in concrete. In the review work, definitions of nanotechnology, including nanoscience and nano-engineering in concrete, were provided. The impact of recent advances in instrumentation and computational materials science and their use in concrete research was discussed. Recent progress in nano-engineering and nanomodification of cement-based materials was presented.

With all these benefits of nano material engineered concrete, concerns remain for scientists and engineers of the wide utilization of particles mixed concrete material. First of all, the toxicity and environmental impact of the ultra-fine nano particles are not yet well studied [18]. Secondly, it is well acknowledged that most of the nanoscale materials are expensive that limits their use with concrete in industry. Finally, the development of nano engineered concrete is based on advances in the materials science. Considerable effort is required to transfer and implement the knowledge gained at the material level to structural engineering and design.

In the recent study, novel UHPC material with nano material addition had been developed. Influence from different nano particles additions was experimentally studied. A series of uniaxial compressive and four point bending tests were conducted in the laboratory to get the static material properties. It was observed that the concrete strength, ductility and energy absorbing ability were all improved comparing with normal strength concrete without fibre and nano additions. Furthermore, to observe the blast resistance of this new material, a series of field blast tests were carried out on columns made of this UHPC. In the present study, the static and blast tests results are summarized. Numerical models based on laboratory tests are developed and calibrated. Field blast tests are reproduced through numerical simulations, and it is demonstrated that the proposed numerical models can well represent the UHPC dynamic behaviour under blast loads.

\section{LABORATORY STATIC TESTS}

\subsection{MATERIALS}

In the current study, the base mix proportion of UHPC material is shown in Table 1 .

Table 1. Base mix proportion of UHPC

\begin{tabular}{lccccc} 
Component & $\begin{array}{c}\mathbf{5 2 . 5} \text { Portland } \\
\text { Cement }\end{array}$ & $\begin{array}{c}\text { Silica } \\
\text { Fume }\end{array}$ & Sand & $\begin{array}{c}\text { Super } \\
\text { plasticizer }\end{array}$ & Water \\
\hline Mass $(\mathrm{kg})$ & 750 & 415 & 1030 & 16 & 190 \\
\hline
\end{tabular}

As can be noticed from the base mix of UHPC, the traditional coarse aggregates $(9.5 \mathrm{~mm}$ to $37.5 \mathrm{~mm}$ in diameter) are replaced by the ultra-fine silica fume $(0.15-0.20 \mu \mathrm{m}$ in diameter). The addition of silica fume can significantly improve material properties of UHPC, in 
particular its compressive strength, bond strength and abrasion strength. Silica fume can also reduce the permeability of concrete and thus protect the steel reinforcement against possible corrosion [19] in chloride rich environment like coastal area.

Fibre reinforcement including four different steel fibres, i.e. MF06, MF15, TF03 and TF05 as shown in Figure 2 are used in the UHPC material at a constant volume fraction of $2.5 \%$.

The material properties and dimensions of the steel fibres are listed in Table 2.

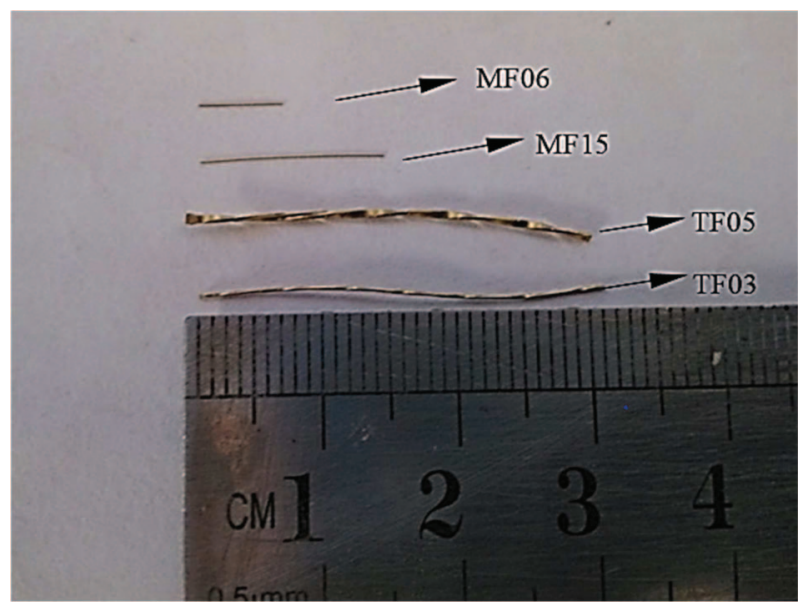

Figure 2. Different types of steel fibres

Table 2. Material properties of steel fibres

\begin{tabular}{lccccc} 
Type & $\begin{array}{c}\text { Elastic } \\
\text { Modulus } \\
(\mathbf{G P a})\end{array}$ & $\begin{array}{c}\text { Tensile } \\
\text { Strength } \\
(\mathbf{M P a})\end{array}$ & $\begin{array}{c}\text { Diameter } \\
(\mathbf{m m})\end{array}$ & $\begin{array}{c}\text { Length } \\
(\mathbf{m m})\end{array}$ & $\begin{array}{c}\text { Aspect } \\
\text { ratio } \\
(\mathbf{L} / \mathbf{D})\end{array}$ \\
\hline MF06 & 210 & 4295 & 0.12 & 6 & 50 \\
MF15 & 210 & 4295 & 0.12 & 15 & 125 \\
TF03 & 210 & 1500 & 0.3 & 30 & 100 \\
TF05 & 210 & 1500 & 0.5 & 30 & 60 \\
\hline
\end{tabular}

Four nano materials including Nano- $\mathrm{CaCO}_{3}, \mathrm{Nano}-\mathrm{SiO}_{2}, \mathrm{Nano}-\mathrm{TiO}_{2}$ and $\mathrm{Nano}-\mathrm{Al}_{2} \mathrm{O}_{3}$ are added into the base mix of UHPC at $3 \%$ volume fraction.

All UHPC samples were produced by mixing the silica fume, fine sand and powder materials which consisted of cement and nanoparticles, in a laboratory concrete mixer. They were firstly dry mixed for 5 minutes before any water addition. Then $70 \%$ water was added and mixed for 3 minutes to fluidise the mix. Superplasticizer was added before the other $30 \%$ water was finally mixed. The mixing process was then continued for another 5 minutes before steel fibres were added and manually dispersed in order to avoid clumping and guarantee the fibres were uniformly distributed and randomly oriented.

In the laboratory, in order to observe the influence from the addition of different nano materials and steel fibres, uniaxial compression tests were carried out on UHPC material with various nano particles and steel fibres mixtures. In the flexural tensile tests, iconic UHPC material with Nano- $\mathrm{CaCO}_{3}$ and MF15 additions was tested to demonstrate its tensile capacity. In the field blast tests, reinforced concrete column constructed with the same material as used in the flexural tensile tests were tested under free air explosions. 


\subsection{UNIAXIAL COMPRESSION TESTS}

Quasi-static compression tests for UHPC specimens were conducted on a number of $100 \mathrm{~mm} *$ $100 \mathrm{~mm} * 100 \mathrm{~mm}$ cubes using a $3000 \mathrm{kN}$ capacity computer-controlled electromechanical servo hydraulic pressure testing machine which conformed to the China standard GB/T 50081-2002. Figure 3 illustrates a cubic specimen that was used in the tests. At both sides of the loading plate, there was an axially oriented LVDT for the test data record. In the test, the loading was displacement controlled.

Static stress-strain curves obtained from samples with different nano additions are depicted in Figure 4. It can be observed that when the same steel fibres i.e. micro steel fibre MF15 were used as UHPC reinforcements, different nano material additions had significant influence on the concrete compressive strength. UHPC with $3 \%$ of $\mathrm{Nano}^{-\mathrm{TiO}_{2}}$ had the highest strength which is about $14 \%$ higher than the lowest compressive strength measured from UHPC with Nano- $\mathrm{Al}_{2} \mathrm{O}_{3}$. Addition of Nano- $\mathrm{CaCO}_{3}, \mathrm{Nano}-\mathrm{SiO}_{2}$ provided slightly higher compressive strength than $\mathrm{Nano}-\mathrm{Al}_{2} \mathrm{O}_{3}$. Among all the nano materials, Nano- $\mathrm{CaCO}_{3}$ in UHPC mix seemed yielding the lowest material ductility, post peak compressive strength quickly dropped to around $60 \mathrm{MPa}$ and then entered a stress plateau. UHPC specimens with addition of the other three nano materials exhibited prominent material ductility. The compressive strength of these three materials remain high (exceed $120 \mathrm{MPa}$ ) even after entering the stress plateau.

Static stress-strain curves representing samples with same Nano- $\mathrm{CaCO}_{3}$ addition but different steel fibres reinforcement are shown in Figure 5. It can be clearly observed that with the addition of different steel fibres in the UHPC, the static performance varies significantly. UHPC with $2.5 \%$ MF15 has the highest static strength around $150 \mathrm{MPa}$ which is about $30 \%$ higher than the lowest strength obtained in UHPC with $2.5 \%$ TF05 reinforcement. It is also noted that with same fibre material, increment in the aspect ratio exerts positive influence on the mechanical performance of UHPC. MF15 (L/D = 125) outperforms MF06 (L/D = 50) while TF03 (L/D = 100) outperforms TF05 (L/D = 60).

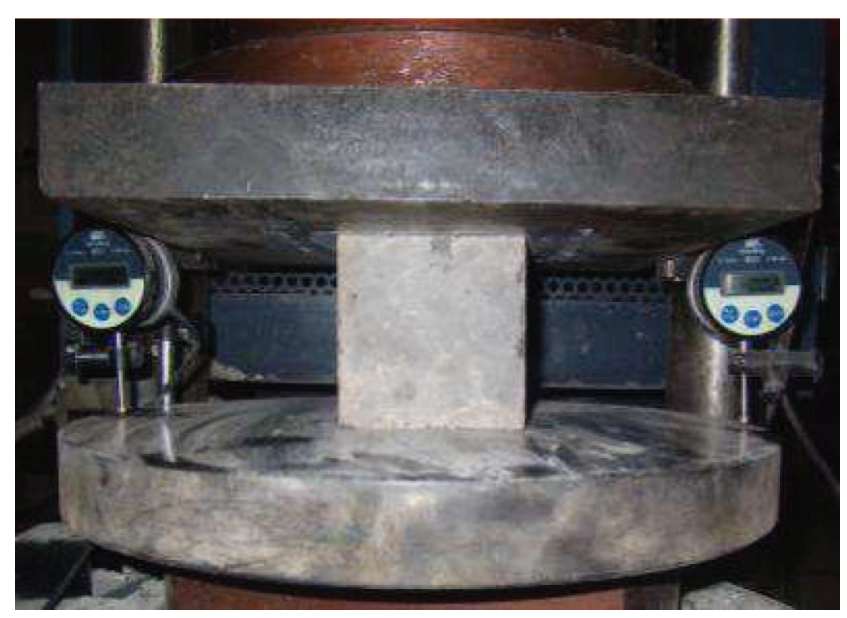

Figure 3. Test setup for compression tests 


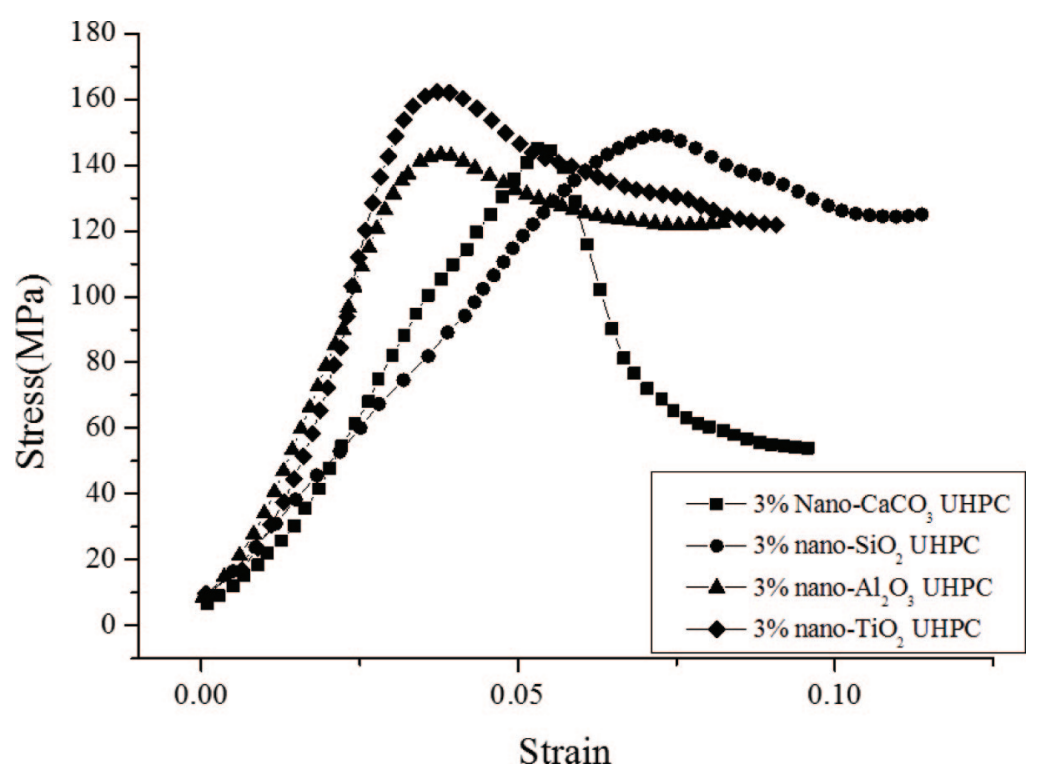

Figure 4. Effects of different nano additions

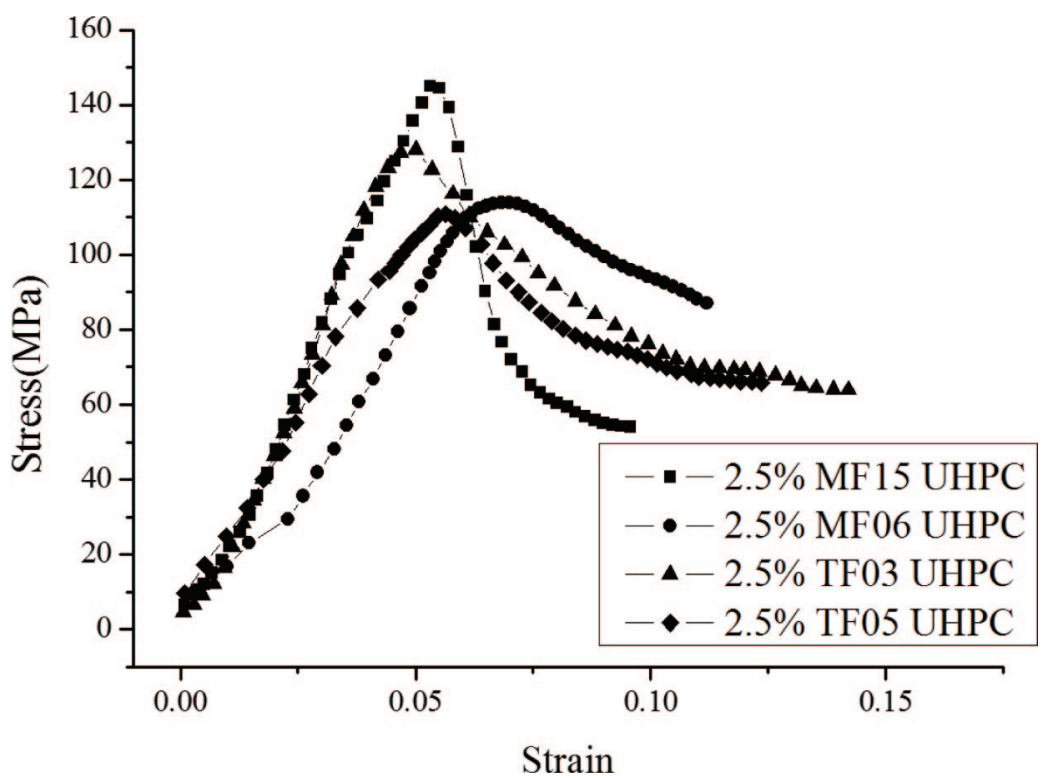

Figure 5. Effects of different steel fibre additions

\subsection{FLEXURAL TENSILE TESTS}

To explore the tensile capacity of the UHPC, four points bending tests were conducted on UHPC specimens with nano-CaCO3 addition and MF15 reinforcement. The samples all have a dimension of $100 \mathrm{~mm} * 100 \mathrm{~mm} * 400 \mathrm{~mm}$ as shown in Figure 6. The spacing between loading points was set to be $1 / 3$ of the clear (outer) span which is $300 \mathrm{~mm}$. Within the loading points, no shear acts and the specimens were solely subjected to bending moments. The 


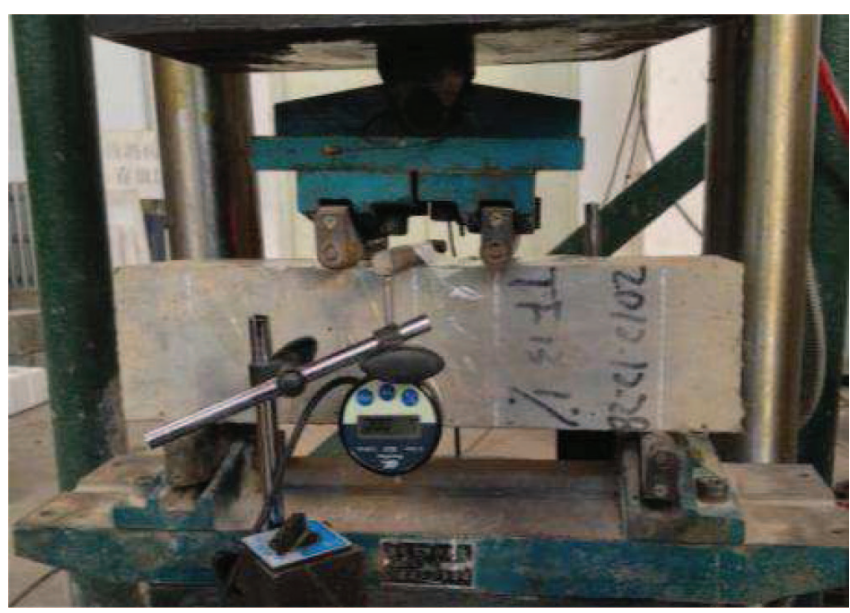

Figure 6. Setup of the flexural tensile tests

central deflection was measured by LVDTs at mid-span and at the supports. Strain gauges were installed along the depth of the specimens at mid span to generate the experimental curvature profiles.

A typical load deflection curve obtained from four points bending test is shown in Figure 7. For a rectangular sample under a load in a four-point bending setup where the loading span is one-third of the support span, the flexural strength is calculated as:

$$
\sigma=\frac{F L}{b d^{2}}
$$

where $F$ is the load (force) at the fracture point, $L$ is the length of the clear span; $b$ is the width; $d$ is the thickness of the sample cross section.

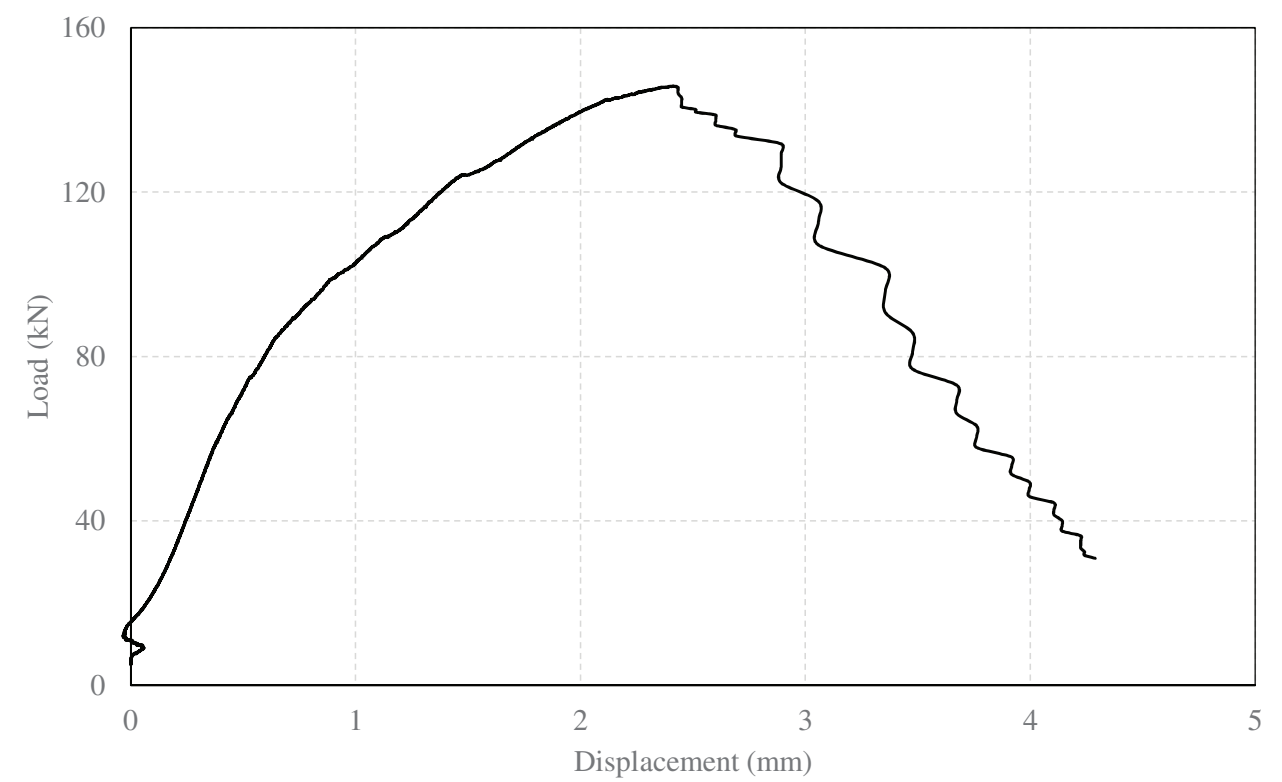

Figure 7. Load versus deflection curve for UHPC 
In this case, after substituting $F$ value of $137 \mathrm{kN}, L$ value of $0.3 \mathrm{~m}, b$ value of $0.1 \mathrm{~m}$ and $d$ value of $0.1 \mathrm{~m}$ into Equation 1, the flexural tensile strength of the UHPC sample can be simply derived as $41 \mathrm{MPa}$. After conducting all four point bending tests, the flexural tensile strength of the UHPC sample is averaged as $36 \mathrm{MPa}$ which is significantly higher than normal strength concrete.

\section{FIELD BLAST TESTS}

\subsection{TEST PROGRAM}

In the field blast tests, four UHPC columns with $2.5 \mathrm{~m}$ span length, and rectangular cross section of $0.2 \mathrm{~m} \times 0.2 \mathrm{~m}$ are tested. The UHPC material used in column construction has Nano- $\mathrm{CaCO}_{3}$ addition and MF15 reinforcement. The geometry of the UHPC column, layout of the longitudinal reinforcements and spacing of the transverse reinforcement are shown in Figure 8.

Testing system is shown in Figure 9. The column is placed on a steel supporting rig and then descended to the ground level. Both ends of the column are fixed using steel bolts, and two strips of rubber sheet are used to cover the gaps between the column and ground support. Such design is proved to be effective for resisting the blast wave passing through the gaps and destroying the testing instruments installed beneath the column. Emulsion explosive, with a TNT equivalence factor $1 / 1.4=0.71$, i.e. $0.71 \mathrm{~kg}$ of TNT is equal to $1 \mathrm{~kg}$ of emulsion
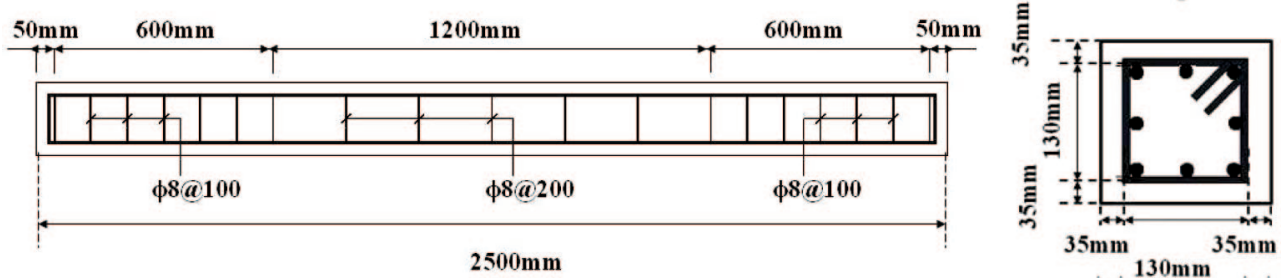

Figure 8. configuration of UHPC columns
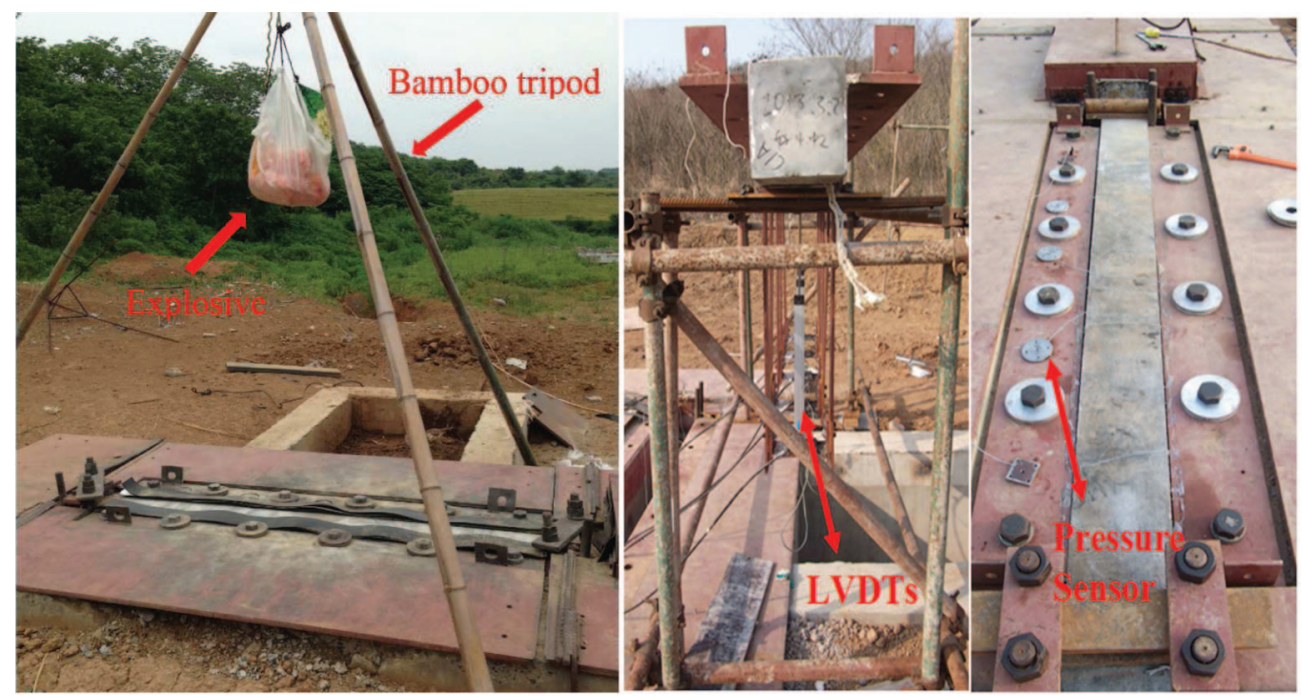

Figure 9. Testing system 
explosive, is used in the test. Explosive is hung over the column at a height of $1.5 \mathrm{~m}$. The explosive is stabilised by a bamboo tripod.

Three LVDTs with a stroke of up to $300 \mathrm{~mm}$ are placed beneath the column on the distal surface to record the column deflection, and all the LVDTs are attached to the slab using a Dynabolt. The sample rate for the LVDTs was $0.2 \mathrm{MHz}$. For measuring the reflected pressure acting on the column, pressure transducers are installed at $0 \mathrm{mmm}, 380 \mathrm{~mm}$ and $760 \mathrm{~mm}$ away from the centre of the specimen, respectively as shown in Figure 9.

The testing program is listed in Table 3. U1B1 and U1B2 are tested without static axial force. U2B1 and U2B2, are tested with a static axial load of $1000 \mathrm{kN}$ (102 ton) applied before blasting test through a hydraulic jack which is buried underground and located axially to the specimen end.

Table 3. Field blast test program

\begin{tabular}{lcccc} 
Column & $\begin{array}{c}\text { Axial } \\
\text { Force }(\mathbf{k N})\end{array}$ & $\begin{array}{c}\text { Charge distance } \\
\mathbf{D}(\mathbf{m})\end{array}$ & $\begin{array}{c}\text { TNT equivalent } \\
\text { charge weight } \mathbf{( k g )}\end{array}$ & $\begin{array}{c}\text { Scaled distance } \\
\left(\mathbf{m} / \mathbf{k g}^{\mathbf{1} / \mathbf{3}}\right)\end{array}$ \\
\hline U1B1 & 0 & 1.5 & 1 & 1.5 \\
U1B2 & 0 & 1.5 & 17.5 & 0.58 \\
U2B1 & 1000 & 1.5 & 1 & 1.5 \\
U2B2 & 1000 & 1.5 & 17.5 & 0.58 \\
\hline
\end{tabular}

\subsection{FIELD TEST RESULTS}

The test results are summarized in Table 4. It should be noted that the pressure information is gathered from the central pressure gauge. The deflection time history is obtained from the LVDT installed at the column mid span.

As can be noticed from the test results, UHPC columns have superior blast resistance capacity. Without axial load, the column under $17.5 \mathrm{~kg}$ TNT equivalent explosion at a $1.5 \mathrm{~m}$ standoff distance experiences a maximum deflection at mid-span of $63.74 \mathrm{~mm}$. With inclusion of 100 ton axial load, the column central deflection decreases to $29.27 \mathrm{~mm}$. This is because the axial load applied to the column generates an initial compressive stress in the concrete, which compensates the tensile stress in the column owing to lateral explosive load and reduces the flexural responses. Another possible reason is that the application of axial load changes the boundary condition of the specimen as it restrains the column ends rotation whilst the column ends can rotate freely in the case without applying the axial load. The influence from the boundary change outweighs the P-Delta effect and thus results in a reduced mid-span deflection.

Table 4. Field blast test results

\begin{tabular}{lccccccl} 
Charge & $\begin{array}{c}\text { Maxial } \\
\text { weight } \\
\text { (kg) }\end{array}$ & $\begin{array}{c}\text { load } \\
(\mathbf{k N})\end{array}$ & $\begin{array}{c}\text { Meflected } \\
\text { Pressure } \\
\text { (MPa) }\end{array}$ & $\begin{array}{c}\text { Duration } \\
\text { (sec) }\end{array}$ & $\begin{array}{c}\text { Impulse } \\
(\text { MPa.ms) }\end{array}$ & $\begin{array}{c}\text { Maximum } \\
\text { deflection } \\
(\mathbf{m m})\end{array}$ & $\begin{array}{l}\text { Postast } \\
\text { damage } \\
\text { level }\end{array}$ \\
\hline U1B1 & 1 & 0 & 2.849 & 0.0009 & 1.218 & 1.96 & light \\
U1B2 & 17.5 & 0 & 37.0 & 0.0006 & 6.51 & 63.74 & moderate \\
U2B1 & 1 & 980 & 1.761 & 0.0011 & 0.964 & 1.24 & light \\
U2B2 & 17.5 & 980 & - & - & - & 29.27 & moderate
\end{tabular}

Note: - indicates a faulty value. 


\section{NUMERICAL SIMULATION}

Numerical simulation of the concrete structure response under explosive loads is a topic of interests in recent academic researches. Successful implementations of numerical models that give good simulations can be found in the open literature [20-26], in which various damage modes including flexural damage, shear damage, concrete spall damage and structural progressive collapse [27] were reproduced through numerical methods. In the current study, numerical model describing the behaviour of UHPC with $\mathrm{Nano}-\mathrm{CaCO}_{3}$ and MF15 additions is established in LS-DYNA based on the test data obtained from laboratory static tests. The accuracy of the numerical model is verified by comparing the numerical simulation and testing results.

\subsection{MATERIAL MODEL AND MATERIAL EOS}

It is known that LS-DYNA has built-in material models such as "Concrete Damage Model", "Johnson-Holmquist-Concrete Model" and "Brittle Damage Model" that can be used to simulate the concrete mechanical behaviour under external loads. However, some of these models involve too many parameters to be determined through simple material tests like uniaxial compression and four points bending. It was also noted that these models cannot well handle the concrete softening behaviour which is quite obvious and important in the UHPC with steel fibre reinforcement. Remarkably, the Elastic-Plastic Hydrodynamic Model (Material Type 10 in LS-DYNA) is applicable to a wide range of materials include those with pressure dependent yielding behaviours. It was reported in the previous work that this model was able to reproduce the dynamic performance of steel fibre reinforced concrete [28-30]. Material Type 10 allows user defined effective stress-effective plastic strain curve to be inputted for the material nonlinear softening definition, and this curve can be easily obtained from simple uniaxial compressive tests in the laboratory. In the present study, the effective stress-effective plastic strain curve can be derived in tabulated form as shown in Table 5.

Table 5. Effective stress-effective plastic strain data for describing UHPC softening (based on Figure 5)

\begin{tabular}{lcclcc} 
& $\begin{array}{c}\text { Effective } \\
\text { plastic strain }\end{array}$ & $\begin{array}{c}\text { Effective } \\
\text { stress (MPa) }\end{array}$ & & $\begin{array}{c}\text { Effective } \\
\text { plastic strain }\end{array}$ & $\begin{array}{c}\text { Effective } \\
\text { stress (MPa) }\end{array}$ \\
\hline Point 1 & 0 & 130 & Point 9 & 0.065 & 90 \\
Point 2 & 0.0025 & 135 & Point 10 & 0.0667 & 81 \\
Point 3 & 0.004 & 140 & Point 11 & 0.07 & 72 \\
Point 4 & 0.0055 & 145 & Point 12 & 0.0745 & 65 \\
Point 5 & 0.0095 & 139 & Point 13 & 0.08 & 60 \\
Point 6 & 0.0115 & 128 & Point 14 & 0.084 & 58 \\
Point 7 & 0.0135 & 115 & Point 15 & 0.09 & 55 \\
Point 8 & 0.0155 & 102 & Point 16 & 0.092 & 54 \\
\hline
\end{tabular}

The effective stress, $\bar{\sigma}$, and the effective plastic strain, $\bar{\varepsilon}^{p}$, herein are defined as follows, respectively:

$$
\bar{\sigma}=\left(\frac{3}{2} S_{i j} S_{i j}\right)^{\frac{1}{2}}
$$




$$
\bar{\varepsilon}^{p}=\int_{0}^{t}\left(\frac{2}{3} D_{i j}^{p} D_{i j}^{p}\right)^{\frac{1}{2}} d t
$$

where $S_{i j}$ represents the deviatoric stress tensor $\left(S_{i j}=\sigma_{i j}-\delta_{i j} \sigma_{k k} / 3\right), t$ is the duration time and $D_{i j}^{p}$ is the plastic strain rate.

To use the Material Type 10, an Equation of State is required in the LS-DYNA. In the present study, the Gruneisen EOS is used. With cubic shock velocity-particle velocity, the Gruneisen equation of state defines pressure for compressed material as:

$$
p=\frac{\rho_{0} C^{2} \mu\left[1+\left(1-\frac{\gamma_{0}}{2}\right) \mu-\frac{a}{2} \mu^{2}\right]}{\left[1-\left(S_{1}-1\right) \mu-S_{2} \frac{\mu^{2}}{\mu+1}-S_{3} \frac{\mu^{3}}{(\mu+1)^{2}}\right]^{2}}+\left(\gamma_{0}+a \mu\right) E
$$

and for expanded material as:

$$
p=\rho_{0} C^{2} \mu+\left(\gamma_{0}+a \mu\right) E
$$

where $C$ is the intercept of the $V_{\mathrm{s}}-V_{\mathrm{p}}$ curve, $S_{1}, S_{2}$ and $S_{3}$ are the coefficients of the slope of the $V_{\mathrm{s}}-V_{\mathrm{p}}$ curve; $\gamma_{0}$ is the Gruneisen gamma; $a$ is the first order volume correction to $\gamma_{0}$; and $\mu=\rho / \rho_{0}-1$.

The parameter in the EOS used in the present study is shown in Table 6.

Table 6. Parameter for the equation of state

\begin{tabular}{ccc}
\hline & $C_{0}$ & $2100 \mathrm{~m} / \mathrm{s}$ \\
\cline { 2 - 3 } $\operatorname{EOS}$ & $S_{1}$ & 1.4 \\
\cline { 2 - 3 } & $\gamma_{0}$ & 2 \\
\hline
\end{tabular}

\subsection{STRAIN RATE EFFECT}

It is commonly acknowledged that concrete material under high strain rate loading condition performs differently than under static loads. The influence from the rate of loading is modelled by Dynamic Increase Factor (DIF). For conventional concrete material, DIFs in compression and tension can be calculated through analytical functions listed in [31]. However it is worth noting that these analytical formulae are derived based on large number of small concrete specimens and their validity for full scale concrete members with different configurations and stress states is not fully investigated. For high strength steel fibre reinforced concrete, limited research on the strain rate effect is found in open literature. In the work conducted by Ngo et al. [32], they proposed DIF model for high strength concrete with compressive strength reaching $160 \mathrm{MPa}$, and the highest DIF value of 1.5 was obtained at a strain rate of $300 \mathrm{~s}-1$. This value is significantly smaller than normal strength concrete. In the numerical simulation conducted by Teng et al. [28], a constant DIF value of 1.5 is used for steel fibre reinforced high strength concrete under impact load. This simplification might result in overestimation of the ultimate resistance of a concrete member. In the work conducted by Wang et al. [29], although no strain rate effect is considered in the numerical modelling, their model well reproduced the projectile penetration of steel fibre reinforced concrete target.

Regarding the UHPC material in the current study, to avoid overestimation on the blast resistance, no strain rate enhancement is considered in the following numerical simulation. 


\subsection{FE MODELLING OF STATIC TESTS}

To verify the analytical model and model parameters given above, behaviours of UHPC under uniaxial compression and four points bending loads are simulated.

\subsubsection{Compression tests}

In the current analysis, the bottom plate is constrained with all degrees of freedom and the top plate only allows displacement along the loading direction, i.e. Z-axis as shown in Figure 10. Both plates are modelled using rigid body in LS-DYNA. The static displacement load is applied by BOUDARY_PRESCRIBED_MOTION_RIGID.

Convergence test was conducted through comparison among the $1 \mathrm{~mm}$ mesh size, $2 \mathrm{~mm}$ mesh size and $5 \mathrm{~mm}$ mesh size. It was observed that, using $1 \mathrm{~mm}$ and $2 \mathrm{~mm}$ mesh size generate similar results, however, the computational cost for the $1 \mathrm{~mm}$ mesh size simulation was exceeding 15 hours, so in the present study, $2 \mathrm{~mm}$ mesh size was adopted. In total, the finite element model has 135440 solid elements.

Figure 11 shows the comparison of results from the FE simulation and laboratory test. It can be noticed that the stress strain curve from the FE simulation coincides well with the test results, both the peak and softening behaviour of the UHPC are well captured.
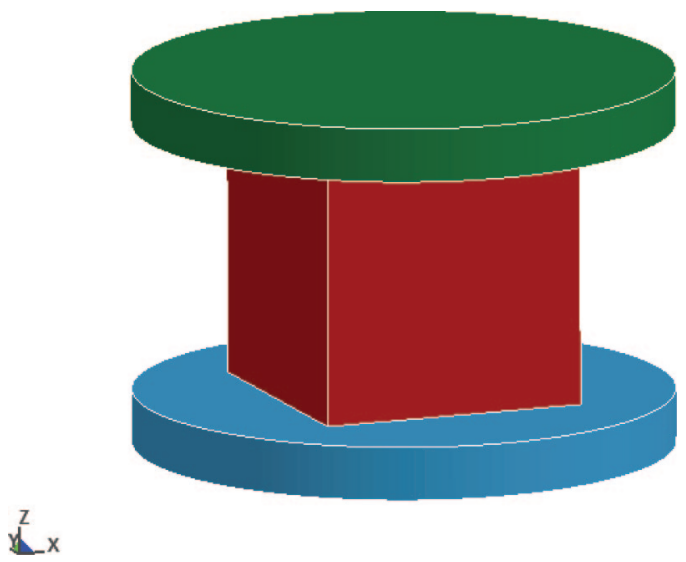

Figure 10. FE model of uniaxial compression test

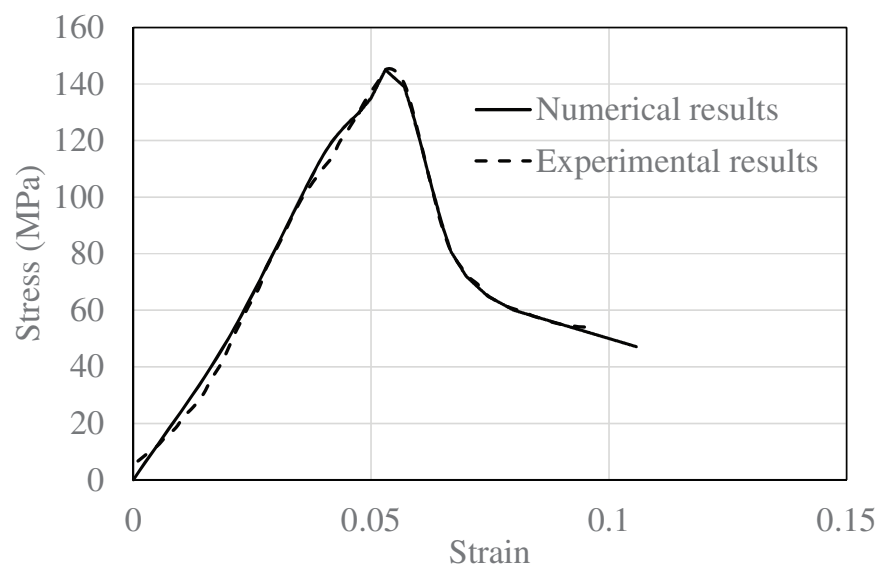

Figure 11. Stress strain curve comparison 


\subsubsection{Four points bending test}

In this section, numerical simulation of the four point bending test is carried out. The above tabulated effective stress-effective plastic strain curve as well as the flexural tensile strength is introduced into the MAT_10 in LS-DYNA. In order to simulate the contact between the specimen and the loading apparatus, CONTACT_AUTOMATIC_SURFACE_TO_ SURFACE is added in the model. Static displacement loading through BOUDARY PRESCRIBED_MOTION_RIGID is applied on the specimen. Figure 12 depicts the FE model, in total there are 532083 solid elements.

Figure 13 presents the simulated results and test data of load-deflection curve. A relatively good agreement is obtained between the numerical and experimental results.

SFRC FOUR POINT BENDING

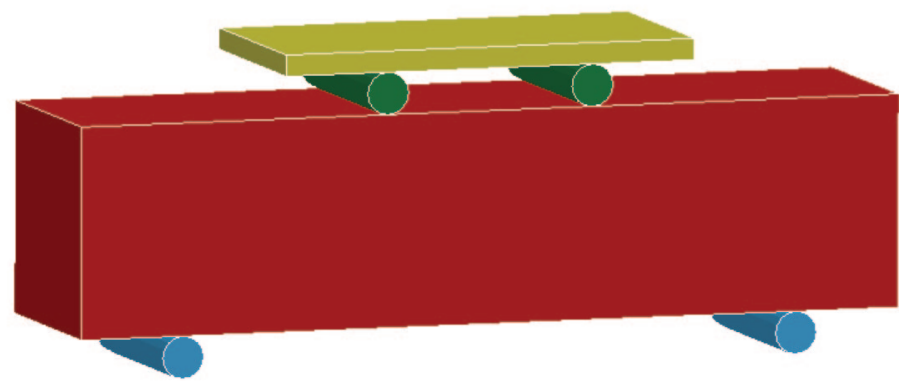

$\mathcal{L}_{x}^{Y}$

Figure 12. FE model for four points bending test

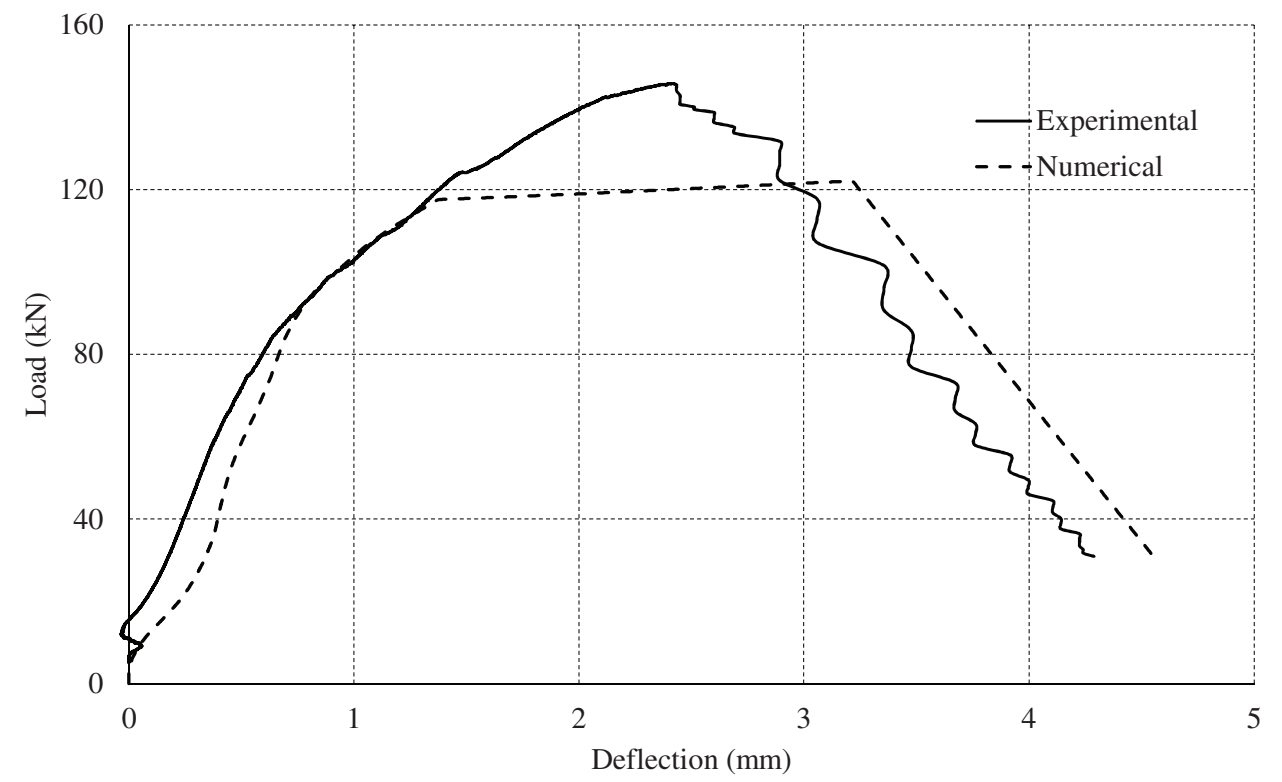

Figure 13. Load deflection curve comparison 
The numerical simulations conducted above confirm the feasibility and validity of the proposed model for UHPC under static loads. In the following section, steel reinforced UHPC columns under blast loads are numerically investigated based on the same material model.

\subsection{NUMERICAL STUDY OF THE FIELD BLAST TESTS}

In the current study, numerical models for UHPC concrete and steel reinforcement are listed in Table 7.

Table 7. Material model and properties

\begin{tabular}{lllc} 
Material & LS-DYNA Model & Input Parameters & Magnitude \\
\hline UHPC & Elastic_Plastic_- & Tabulated effective plastic & \\
& Hydrodynamic & stress versus strain shown & \\
& & in Table 5 & \\
\multirow{3}{*}{ Steel } & Erosion criterion & Principal tensile strain & 0.1 \\
& Piecewise_linear__ & Mass density & $7800 \mathrm{~kg} / \mathrm{m}^{3}$ \\
& plasticity & Elastic modulus & $200 \mathrm{GPa}$ \\
& & Poisson's ratio & 0.3 \\
& & Yield stress & $1350 \mathrm{MPa}$ \\
& & Failure plastic strain & 0.15 \\
\hline
\end{tabular}

\subsubsection{Numerical results}

In the present study, two cases i.e. U1B1 under $1 \mathrm{~kg}$ TNT and U2B2 under $17.5 \mathrm{~kg}$ TNT, are simulated using the proposed numerical model. To capture the dynamic response and possible localized damage on the UHPC column, finite element model with mesh size $0.01 \mathrm{~m}$ is created in LS-DYNA and shown in Figure 14, steel support is also simulated through Mat_Rigid_Body.

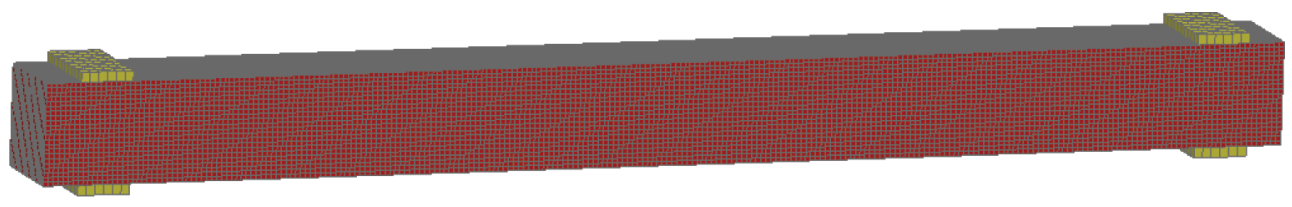

Figure 14. Finite element model

Contact_Automatic_Surface_to_Surface is used to describe the contact between the column and support.

In current study, the blast effect is modelled through LS-DYNA inbuilt function *load_blast_enhanced. The utilization of this function avoids the detailed modelling of the explosive charge and shock wave propagation in air, thus it can save the computational effort. The reliability of this function in simulating blast loads on structures has been proven and it is very commonly used in numerical simulations of structural responses to blast loads $[33,34]$.

Figure 15 displays the U1B1 column response at around $4.6 \mathrm{~ms}$ when a maximum deflection is reached. It can be clearly seen that the stress concentrates at the support and mid span. No damage of the UHPC column is observed. 

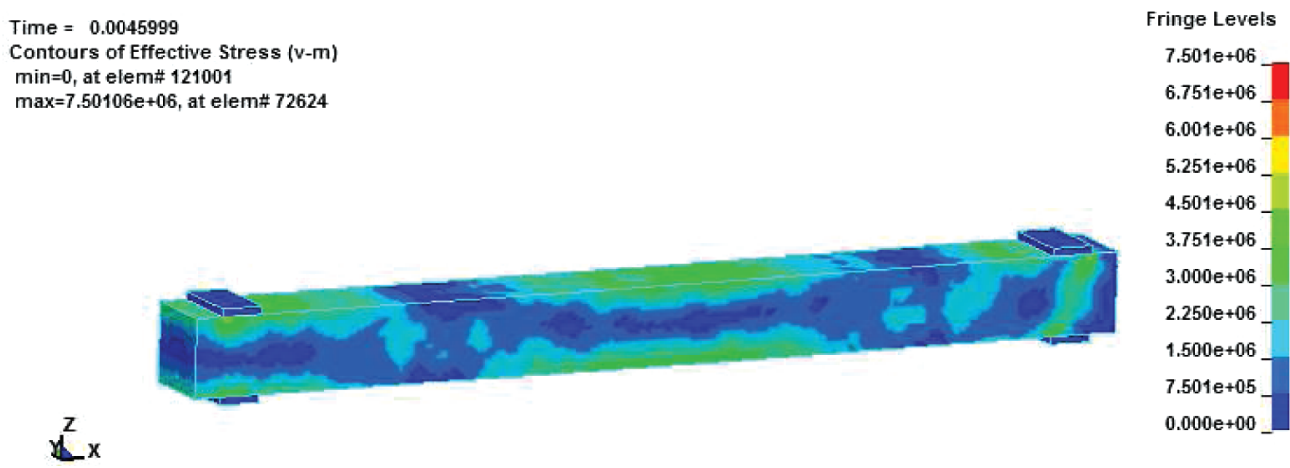

Figure 15. Maximum deflection of UIB1 under $1 \mathrm{~kg}$ TNT

Figure 16 compares the mid-span deflection time history curve. It is noted that the numerical model well captures the maximum deflection and well reproduces time history curve until the first peak. The slight inconsistence afterward can be explained by the fact that in real blast test, the blast energy can be dissipated in multiple ways like column free vibration, friction between the column with boundary and surrounding medium. The friction between column and the roller supports increases the column stiffness. In numerical simulations these are not considered. This results in a slower vibration when compared with the real test.

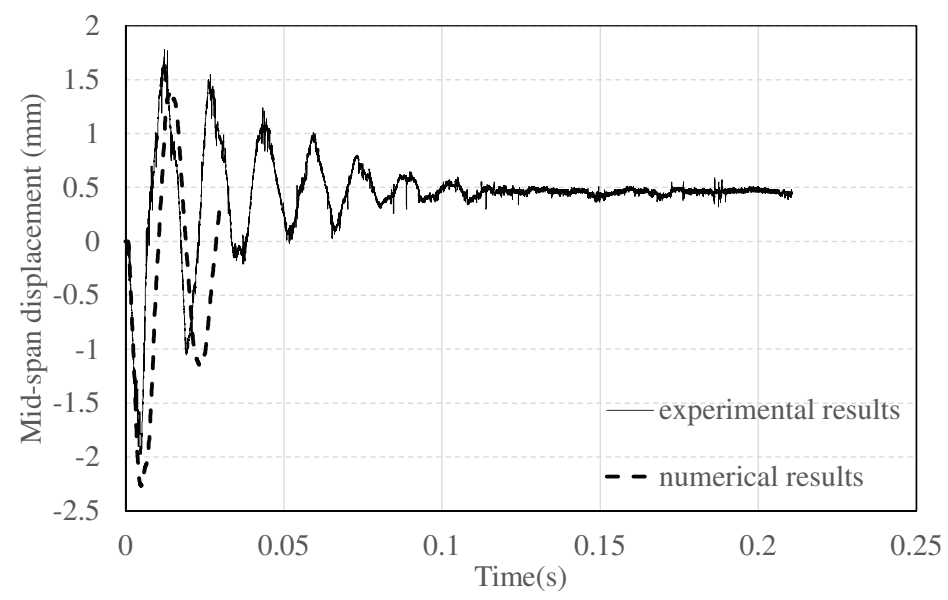

Figure 16. Comparison of deflection time history curve for UlBl under $1 \mathrm{~kg}$ TNT explosion

For U2B2 column subjected to $17.5 \mathrm{~kg}$ TNT equivalent explosion loading, 100 ton axial load is applied on the UHPC column. In the numerical simulation, a pressure of $25 \mathrm{MPa}$ is applied on one end of the column and lasts for the entire simulation. The first $10 \mathrm{~ms}$ is used to stabilise the column after axial load application. It is believed that due to the very high axial stiffness, $10 \mathrm{~ms}$ is enough to dissipate the kinetic energy imparted by the application of axial load in the numerical simulation. Figure 17 shows the column maximum deflection contour at around $7.5 \mathrm{~ms}$. Figure 18 displays the time history curve comparison, and it can be noted that the numerical model yields a highly accurate maximum deflection and good time history curve prediction until the first peak. The same reason summarised in U1A1 case can be used to explain the slight inaccuracy of prediction. 


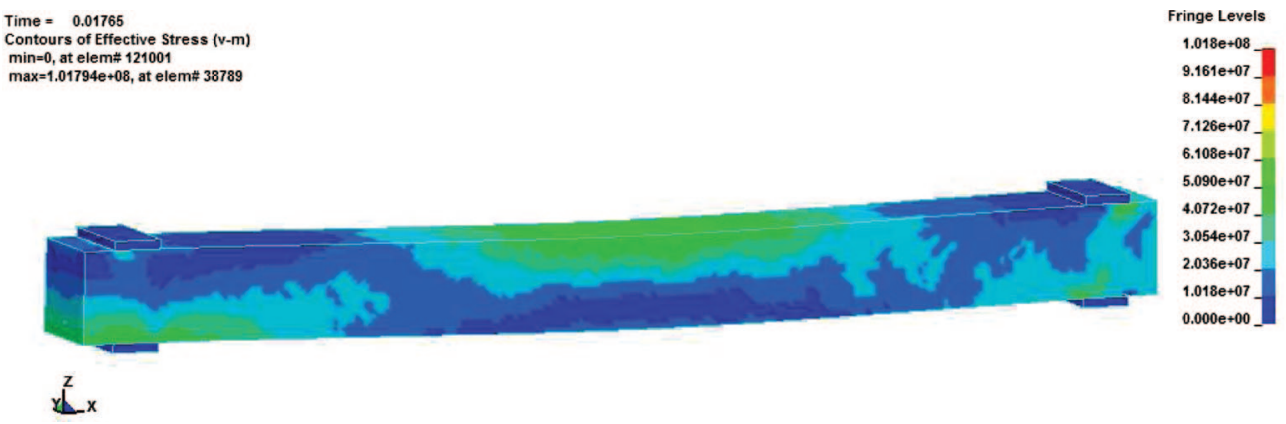

Figure 17. Maximum deflection of U2B2 under $17.5 \mathrm{~kg}$ TNT

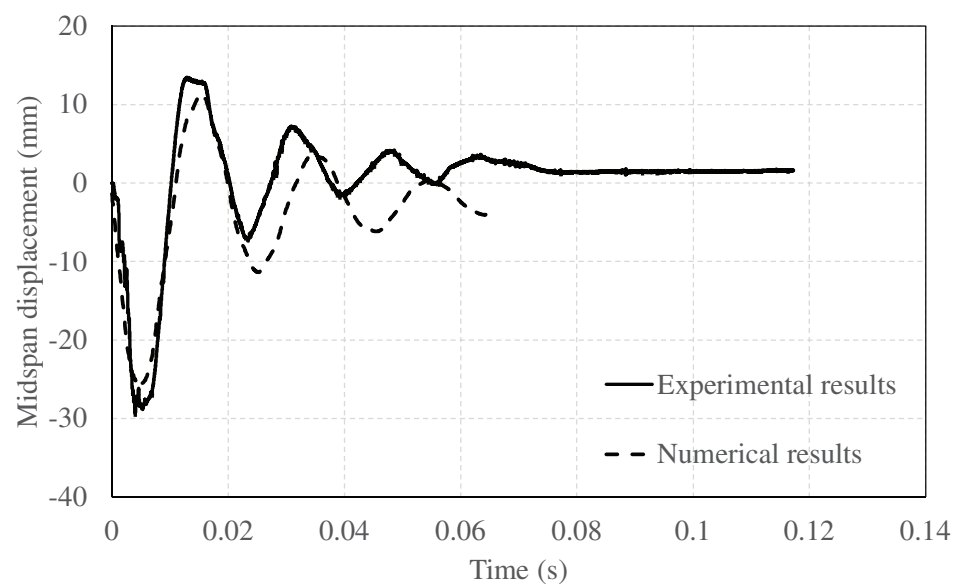

Figure 18. Comparison of deflection time history curve for U2B2 under $17.5 \mathrm{~kg}$ TNT

\section{CONCLUSIONS}

Development of ultra-high strength concrete material is receiving increasing attention in recent decades. With advanced nanotechnology, steel fibre reinforced concrete had been reengineered through nanoscale particle addition. Static tests had revealed the outstanding mechanical properties of this novelty concrete, to further explore the blast resistance of this newly developed UHPC material, a series of field tests had been carried out on UHPC columns. From the field test results, it is concluded that UHPC material with nano addition displays a high blast loading resistance capacity. Based on the static test data, novel numerical models are established, and the numerical simulations on the field tests are found correlating well with the field observation and the time history curves are fitted well with the test data.

\section{ACKNOWLEDGEMENTS}

The research presented in this paper jointly supported by the National Natural Science Foundation of China under Grants 51278326 and 51238007 and the ARC Discovery Grant DP140103025 is gratefully acknowledged. 


\section{REFERENCES}

[1] C. Wu, D.J. Oehlers, M. Rebentrost, J. Leach and A.S. Whittaker, Blast testing of ultra-high performance fibre and FRP-retrofitted concrete slabs, Engineering Structures, 31 (2009) 2060-2069.

[2] V. Bindiganavile, N. Banthia and B. Aarup, Impact Response of Ultra-High-Strength Fiber-Reinforced Cement Composite, ACI materials journal, 99 (2002) 543-548.

[3] R.S.P. Coutts, A review of Australian research into natural fibre cement composites, Cement and Concrete Composites, 27 (2005) 518-526.

[4] S. Rigaud, G. Chanvillard and J. Chen, Characterization of Bending and Tensile Behavior of Ultra-High Performance Concrete Containing Glass Fibers, in: G. Parra-Montesinos, H. Reinhardt, A.E. Naaman (Eds.) High Performance Fiber Reinforced Cement Composites 6, Springer Netherlands, 2012, pp. 373-380.

[5] J. Chen and C. Gilles, UHPC Composites Based on Glass Fibers with High Fluidity, Ductility, and Durability, in: Ultra-High Performance Concrete and Nanotechnology in Construction. Proceedings of Hipermat 2012. 3rd International Symposium on UHPC and Nanotechnology for High Performance Construction Materials, kassel university press GmbH, 2012, pp. 265.

[6] Z.Zheng and D. Feldman, Synthetic fibre-reinforced concrete, Progress in Polymer Science, 20 (1995) 185-210.

[7] N. Buratti, C. Mazzotti and M. Savoia, Post-cracking behaviour of steel and macro-synthetic fibre-reinforced concretes, Construction and Building Materials, 25 (2011) 2713-2722.

[8] Y. Ye, S. Hu, B. Daio, S. Yang and Z. Liu, Mechanical behavior of ultra-high performance concrete reinforced with hybrid different shapes of steel fiber, Bridges, 10 (2014) 9780784412442.9780784412307.

[9] V. Bindiganavile and N. Banthia, Polymer and Steel Fiber-Reinforced Cementitious Composites under Impact Loading. Part 1: Bond-Slip Response, ACI Materials Journal, 98 (2001).

[10] Z. Xu, H. Hao and H. Li, Experimental study of dynamic compressive properties of fibre reinforced concrete material with different fibres, Materials \& Design, 33 (2012) 42-55.

[11] F. Sanchez and K. Sobolev, Nanotechnology in concrete-a review, Construction and Building Materials, 24 (2010) 2060-2071.

[12] Y. Qing, Z. Zenan, K. Deyu and C. Rongshen, Influence of nano-SiO 2 addition on properties of hardened cement paste as compared with silica fume, Construction and Building Materials, 21 (2007) 539-545.

[13] T. Ji, Preliminary study on the water permeability and microstructure of concrete incorporating nano-SiO $\mathrm{S}_{2}$, Cement and Concrete Research, 35 (2005) 1943-1947.

[14] H. Li, H.-g. Xiao, J. Yuan and J. Ou, Microstructure of cement mortar with nano-particles, Composites Part B: Engineering, 35 (2004) 185-189.

[15] Z. Li, H. Wang, S. He, Y. Lu and M. Wang, Investigations on the preparation and mechanical properties of the nano-alumina reinforced cement composite, Materials Letters, 60 (2006) 356-359.

[16] X. Liu, L. Chen, A. Liu and X. Wang, Effect of $\mathrm{Nano}_{-} \mathrm{CaCO}_{3}$ on Properties of Cement Paste, Energy Procedia, 16, Part B (2012) 991-996.

[17] F. Sanchez and K. Sobolev, Nanotechnology in concrete - A review, Construction and Building Materials, 24 (2010) 2060-2071.

[18] O. Bar-Ilan, R.M. Albrecht, V.E. Fako and D.Y. Furgeson, Toxicity assessments of multisized gold and silver nanoparticles in zebrafish embryos, Small, 5 (2009) 1897-1910.

[19] R.J. Detwiler, C.A. Fapohunda and J. Natale, Use of supplementary cementing materials to increase the resistance to chloride ion penetration of concretes cured at elevated temperatures, ACI Materials Journal, 91 (1994).

[20] X. Zhou, V. Kuznetsov, H. Hao and J. Waschl, Numerical prediction of concrete slab response to blast loading, International Journal of Impact Engineering, 35 (2008) 1186-1200.

[21] J. Li and H. Hao, Numerical study of concrete spall damage to blast loads, International Journal of Impact Engineering, 68 (2014) 41-55.

[22] K. Xu and Y. Lu, Numerical simulation study of spallation in reinforced concrete plates subjected to blast loading, Computers \& Structures, 84 (2006) 431-438. 
[23] J. Li and H. Hao, Influence of brittle shear damage on accuracy of the two-step method in prediction of structural response to blast loads, International Journal of Impact Engineering, 54 (2013) 217-231.

[24] J. Li and H. Hao, A two-step numerical method for efficient analysis of structural response to blast load, International Journal of Protective Structures, 2 (2011) 103-126.

[25] J. Li and H. Hao, Development of a Simplified Numerical Method for Structural Response Analysis to Blast Load, Procedia Engineering, 14 (2011) 2558-2566.

[26] Y. Xia, C. Wu, F. Zhang, Z.-X. Li and T. Bennett, Numerical Analysis of Foam-Protected RC Members Under Blast Loads, International Journal of Protective Structures, 5 (2014) 367-390.

[27] J. Li and H. Hao, Numerical study of structural progressive collapse using substructure technique, Engineering Structures, 52 (2013) 101-113.

[28] T.-L. Teng, Y.-A. Chu, F.-A. Chang, B.-C. Shen and D.-S. Cheng, Development and validation of numerical model of steel fiber reinforced concrete for high-velocity impact, Computational Materials Science, 42 (2008) 90-99.

[29] Z.L. Wang, J. Wu and J.G. Wang, Experimental and numerical analysis on effect of fibre aspect ratio on mechanical properties of SRFC, Construction and Building Materials, 24 (2010) 559-565.

[30] D.-Y. Yoo and Y.-S. Yoon, Influence of steel fibers and fiber-reinforced polymers on the impact resistance of one-way concrete slabs, Journal of Composite Materials, 48 (2014) 695-706.

[31] L.J. Malvar and J.E. Crawford, Dynamic increase factors for concrete, in, DTIC Document, 1998.

[32] T. Ngo, P. Mendis and T. Krauthammer, Behavior of ultrahigh-strength prestressed concrete panels subjected to blast loading, Journal of Structural Engineering, 133 (2007) 1582-1590.

[33] J. Li and H. Hao, A Simplified Numerical Method for Blast Induced Structural Response Analysis, International Journal of Protective Structures, 5 (2014) 323-348.

[34] J. Li and H. Hao, Numerical and Theoretical Study of Concrete Spall Damage under Blast Loads, in: Applied Mechanics and Materials, Trans Tech Publ, 2014, pp. 774-779. 